\title{
Educación artística y teorías implícitas del alumnado de educación secundaria
}

\author{
Artistic education and implicit theories of secondary school students
}

\author{
Cristina NAVARRETE. I.E.S. Doctor Fleming (España). cristinana@educastur.org \\ Carmen RODRÍGUEZ. Universidad de Oviedo (España).carmenrm@uniovi.es \\ José Luis BELVER. Universidad de Oviedo (España). belverjose@uniovi.es
}

Resumen: El presente artículo analiza las teorías implícitas de los estudiantes de la ESO en relación con la Educación Artística y, en concreto, a la materia Educación Plástica Visual y Audiovisual que suponen un obstáculo en el aprendizaje de esta. Para ello se ha diseñado una investigación cualitativa utilizando como instrumentos de recogida de datos la observación participante en el aula de plástica diariamente durante 4 meses y el análisis de contenido de varias actividades gráfico-plásticas realizadas por el alumnado. La muestra está compuesta todos los estudiantes de $3^{\circ}$ de ESO de un instituto del centro de Oviedo divididos en 5 grupos ( 88 alumnos/as en total). La información registrada en el diario de campo se analiza a través de un sistema de categorías que comprende la motivación del alumnado participante ante la materia, el autoconcepto y creencias de autoeficacia del alumnado participante, la calidad de las producciones gráfico-plásticas y otras percepciones del entorno. Los resultados de la investigación constatan que, aunque el alumnado en general valora y muestra interés por la materia, existen una serie de teorías implícitas relacionadas con ciertos mitos que se asocian a la Educación Artística. Esta detección de preconceptos en nuestra área nos permite llevar a cabo una investigación posterior, más amplia, para modificar estas ideas preconcebidas y facilitar su aprendizaje de nuestro alumnado en el ámbito artístico.

Palabras clave: educación secundaria, teorías implícitas, educación artística, autoeficacia, motivación, arte.

Abstract: This article analyzes the implicit theories of ESO students in relation to Art Education and, in particular, to the subject Visual Arts that represent an obstacle 
in the learning of this. For this, a qualitative research has been designed using as instruments of data collection the participant observation in the plastic classroom daily for 4 months and the content analysis of several graphic-plastic activities carried out by the students. The sample is composed of all students of the 3 rd year of ESO in an institute in the center of Oviedo divided into 5 groups (88 students in total). The information recorded in the field diary is analyzed through a system of categories that includes the motivation of the participating students before the subject, the self-concept and self-efficacy beliefs of the participating students, the quality of the graphic-plastic productions and other perceptions of the environment. The results of the research show that, although the students in general value and show interest in the subject, there are several implicit theories related to certain myths that are associated with Art Education. This detection of preconceptions in our area allows us to carry out a later, more extensive investigation, to modify these preconceived ideas and facilitate their learning of our students in the artistic field.

Keywords: secondary education, implicit theories, Artistic Education, self-efficacy, motivation, art.

\section{Introducción y antecedentes}

Los estudiantes opinan, a menudo, que no pueden desarrollar sus capacidades artísticas y, en ocasiones, estas ideas persisten hasta la edad adulta si no conseguimos modificar sus teorías implícitas. Según Barbosa (2004) existe una primera crisis en el arte infantil alrededor de los 6 años y una segunda en torno a los 11/12, cuando los niños y niñas están finalizando la Educación Primaria. Es en esa segunda etapa cuando el niño o niña empieza a perder seguridad en sí mismo y comienza a pensar que no sabe dibujar ya que en esta época el estudiante valora las obras de arte por su parecido con la realidad considerando cualquier obra abstracta como un objeto sin valor. Es en este periodo cuando muchos adolescentes abandonan la actividad plástica, lo que hace que, en muchos casos, lleguen a adultos detenidos en esta fase, si no lo han hecho ya en la primera crisis.

En este contexto, nuestra investigación pretende ahondar en las teorías implícitas que posee el alumnado de enseñanza secundaria para analizar qué relación tienen con su capacidad percibida respecto a la materia de Educación Plástica Visual y Audiovisual (EPVA en adelante).

Las investigaciones que profundizan sobre las teorías implícitas o preconceptos en el alumnado de Educación Secundaria en nuestra materia son escasas; sin embargo, Giráldez (2007) (véase también Acaso, 2009; Araluce, 2017; Reina, 2017) enumera una serie de mitos que hacen referencia a diversas ideas preconcebidas acerca de la Educación Artística que pueden haber perjudicado a las enseñanzas artísticas, relegándolas a un segundo plano. Uno de ellos se refiere a la creencia de que la creación plástica no es un proceso intelectual sino manual, en el que se valora, 
sobre todo, la pericia o el dominio de las técnicas artísticas. Por ello, se considera un pasatiempo, una actividad relajante y poco trascendente. Esto hace que no sea necesario estudiar la materia y fomenta su marginalidad (Acaso, 2009). El hecho de que la Educación Artística se considere un pasatiempo, una 'manualidad' deja a un lado el análisis para centrarse en la producción de objetos utilizando diversas técnicas. En suma, se considera una actividad que no requiere habilidad intelectual sino manual, dando prioridad a lo subjetivo o lo afectivo. Asimismo, Giráldez (2007) alude también a la consideración de las materias artísticas como un complemento del resto, identificándose la educación artística con la creatividad mientras que la ciencia se asocia con la resolución de problemas.

De forma complementaria, existe una idea generalizada de que la creatividad, así como la creación plástica, no se pueden desarrollar (Acaso, 2009; Araluce, 2017; Giráldez, 2007; Reina, 2017), dando lugar al mito del artista genial. Por ello es habitual escuchar en nuestras aulas comentarios como 'yo no sé dibujar' o 'a mí no se me da bien'. En la misma línea, un estudio realizado por Romo (1998) constata la persistencia de la 'Teoría de las dotes innatas' así como la 'Teoría del trastorno psicológico', aquella que asocia el arte con la locura. También Eisner (2002) incide sobre el mito del artista genial:

Un punto de vista, sostenido por el público, considera la educación artística del niño como un resultado del talento, $\mathrm{y}$, dado que el talento es un don, no todos lo poseen. La gente piensa que el talento es como estar embarazada, se tiene, o no se tiene (Eisner, 2002, p.47).

Según Hernández (1995) el mito de que se llega a ser artista gracias a un don de la naturaleza es una construcción social fomentada por críticos, educadores de arte y artistas que favorece la marginalización de la Educación Artística en la sociedad. Nuestra cultura, y en especial el cine, contribuye a perpetuar los estereotipos acerca del artista y nos muestra una idea del mismo como un ser 'caprichoso' y, en ocasiones, con rasgos vinculados a los desórdenes del comportamiento, la depresión o la melancolía (Belinche y Ciafardo, 2006).

Todos estos mitos pueden influir en la pérdida de interés de los estudiantes por la materia, ya que si la Educación Artística depende de las cualidades innatas de cada uno y no hemos nacido con ellas nunca llegaremos a poseerlas y, por tanto, abandonaremos todo esfuerzo para conseguir desarrollar nuestras capacidades artísticas. Además, esto hace pensar que la educación artística solo debe ser estudiada por unos pocos, aquellos que han nacido con ese don innato.

Existen también algunos estudios que analizan las teorías implícitas de futuros docentes de Educación Primaria. Así, Morales-Caruncho y Chacón Gordillo (2018) realizaron una investigación cualitativa en la Universidad de Granada con futuros docentes de educación primaria, concluyendo que estos ponían en duda los mitos 
respecto a la enseñanza de las artes, reivindicando la idea de que la materia no está únicamente relacionada con procesos manuales y que el talento no es innato.

En cuanto a las investigaciones referidas a la Educación Secundaria, Ascaso-Til (2016) realiza un estudio en un centro público de Enseñanza Secundaria de Huesca para analizar la desmotivación del alumnado respecto a la materia de Educación Plástica y Visual. Su objetivo fue analizar si la percepción negativa de la materia que tenía el alumnado provenía de sus impresiones o de ideas trasmitidas por los adultos. El estudio concluyó que el alumnado de Secundaria consideraba la materia de EPV poco útil, siendo resultado esta conclusión de las ideas preconcebidas de los adultos de su entorno más próximo (profesorado no especialista en la materia y familias). Por otro lado, el alumnado disfrutaba de la materia y reclamaba un cambio metodológico que les ayudase a potenciar sus capacidades artísticas. En este contexto, Ascaso-Til (2016) propone que se potencie la idea de que las capacidades artísticas se pueden desarrollar a través de la implementación de diversas estrategias de enseñanza-aprendizaje, puesto que no hablamos de dones innatos.

Es especialmente significativa la aportación de Vaquero y Gómez del Águila (2018), que realizan una investigación con el alumnado que inicia la formación del Grado de Maestro/a en Educación Primaria en la asignatura Educación en Artes Plásticas y Visuales. Durante cuatro cursos académicos se analizaron las opiniones de unos 60 estudiantes al año que reflejaron, a través de cuestionarios, sus teorías implícitas respecto a la Educación Artística. Estas ideas, provenientes en muchos casos de su experiencia en Educación Secundaria, hacen que sea necesario 'deconstruir y casi demoler esquemas mentales' pues los estereotipos deslegitiman la Educación Artística (Vaquero y Gómez del Águila, 2018, p.228). En este sentido, el estudio refleja que existe un alto porcentaje de estudiantes (en algunos casos de casi el 30\%) que espera que la asignatura sea 'entretenida' o 'divertida'. Además, es relevante que más del $50 \%$ de los estudiantes asocie la materia con dibujar o hacer láminas y que exista un número de alumnos considerable (hasta un 33\% en el curso 2016/2017) que asocia la asignatura con las manualidades. Las investigadoras señalan también ciertas actitudes observadas en estudiantes referidas a su bajo grado de autoeficacia, alumnado que considera que 'no se le da bien' dibujar o de desprecio en relación con el panorama artístico actual: 'Eso lo hago yo'.

Con respecto a las creencias de autoeficacia y su relación con las teorías implícitas debemos indicar que la literatura sobre la percepción de las capacidades en la enseñanza artística es muy limitada, destacando especialmente las contribuciones de Lowenfeld y Brittain (1980). Los autores relataban los miedos e inseguridades de los niños y niñas de Educación Primaria, producto de sus ideas previas sobre la materia, que provocaban su incapacidad para trazar una sola línea si no contaban con la aprobación del docente. En este contexto, cuando los estudiantes llegaban a la Educación Secundaria muchas veces habían perdido la desinhibición propia de los dibujos infantiles tratándose de un 'periodo crítico en su evolución' y, en 
ocasiones, su último contacto con la Educación Artística, que abandonaban al acabar la Educación Secundaria.

Por otro lado, y de forma complementaria, si atendemos al constructo 'autoconcepto' debemos reseñar la contribución de Paulov y Kambouri (2007), quienes realizaron un estudio con 420 estudiantes de Educación Primaria (11-12 años) que reflejó que los estudiantes con un elevado autoconcepto mostraban actitudes más positivas hacia el arte, valorando de forma más positiva las actividades artísticas y la tarea del docente.

\section{Diseño de la investigación}

\section{Objetivos}

El principal objetivo de nuestro estudio ha sido detectar las teorías implícitas del alumnado de Educación Secundaria en relación con la Educación Artística, así como sus creencias de autoeficacia respecto a sus capacidades artísticas. Esto nos permitirá, en una segunda fase de la investigación, aplicar y evaluar la metodología didáctica del Aprendizaje Basado en Proyectos como método que mejora el interés, las creencias de autoeficacia y la creatividad del alumnado de E.S.O.

\section{Diseño metodológico}

La investigación se propone desde un enfoque cualitativo, de carácter etnográfico, en el que la investigadora, al realizar también la labor de profesora, está presente en todas las etapas de la investigación y forma parte de todo el proceso como sujeto participante para reflexionar sobre la propia práctica educativa. Como afirma Díaz de Rada (2011), todo etnógrafo realiza una observación participante puesto que éste siempre se encuentra en el campo, donde ocurre la acción social y no puede evitar ser partícipe de lo que allí ocurre. Esto se acentúa, en nuestro caso, ya que además de tratarse de una etnografía en el ámbito de la educación escolar, nuestra posición es la del agente que estructura la clase y no un mero observador. El contexto de observación ha sido el aula de plástica, lugar donde se llevan a cabo las actividades, $\mathrm{y}$, en algunos casos, el aula de referencia de cada grupo.

El acceso al campo se produce de forma natural, con el inicio de curso, tras presentar el proyecto a la dirección del centro. Además, se solicita el permiso y se informa personalmente a las familias del alumnado participante en una reunión inicial. El anonimato del alumnado se respeta desde el primer momento, por lo que los nombres han sido modificados. 


\section{Técnicas de recogida de información}

En el contexto de la metodología cualitativa de tipo investigación-acción que proponemos, se plantean varias técnicas de recogida de datos buscando la triangulación: Observación participante, entrevistas y otros contactos con familias (integradas en el diario de campo) y actividades realizadas por el alumnado.

La observación participante dio lugar al desarrollo de un diario de campo que registra, durante todas las clases desarrolladas en el primer semestre del curso (dos horas con cada uno de los cinco grupos), las impresiones del alumnado respecto a la materia. En el cuarto mes de estudio se incorporan a las clases una alumna y un alumno del Máster de Formación del Profesorado de Educación Secundaria cuyas observaciones son registradas también en nuestro diario.

Finalizado el primer trimestre del curso, podemos distinguir una segunda fase en la que se introduce un primer proyecto colaborativo ¿Por qué educación artística? en el que los ejercicios realizados por los estudiantes, tanto por escrito como gráficoplásticos, suponen también una gran fuente de información para nuestro estudio.

\section{Participantes}

Se trata de un estudio de casos múltiples en el que nos centramos en un grupo de estudiantes de Educación Secundaria Obligatoria. Para la realización de la investigación se tomó como muestra el alumnado matriculado en un Instituto de Enseñanza Secundaria situado en Oviedo que acoge una mayoría de estudiantes de colegios públicos del entorno y una minoría de colegios rurales cercanos. En concreto se realizó con el alumnado de $3^{\circ}$ de ESO (88 estudiantes divididos/as en 5 grupos) durante el curso 2017-18. El grupo A compuesto por 15 estudiantes (entre ellos un alumno con discapacidad auditiva que cuenta con una intérprete en el aula), el grupo B, compuesto por 22 estudiantes, los grupos C y D, con 20 estudiantes cada uno, y el grupo de PMAR (Programa de mejora y aprendizaje) con 9 alumnos/ as. El alumnado está repartido equitativamente por sexos dentro de cada grupo, asimismo, existe similar número de alumnos/as bilingües y no bilingües. Todo el alumnado de $3^{\circ}$ de ESO cursa obligatoriamente la materia de EPVA.

\section{Análisis de resultados}

Una vez recogidos todos los datos a lo largo del primer cuatrimestre del curso 2017/18, el siguiente paso ha sido el análisis de estos, los que nos permitió establecer conclusiones y abrir posibles vías de discusión. Para realizar nuestro análisis comenzamos planteando una serie de posibles categorías a partir de las preguntas de investigación, de esta forma obtuvimos una lista de ideas o tópicos clave que se fueron modificando según se analizaba toda la información. Así, pasamos de un razonamiento deductivo a otro más inductivo en el que se realizó 
NAVARRETE, RODRÍGUEZ \& BELVER / Educación artística y teorías implícitas del alumnado de educación secundaria

una codificación abierta, distinguiendo entre categorías y subcategorías. Una vez analizada la información contenida en los diversos documentos a partir de las categorías previamente establecidas, se seleccionó todo aquello que cumplía los criterios de pertinencia y relevancia según recomienda Cisterna (2005).

Tabla 1

Categorías y subcategorías

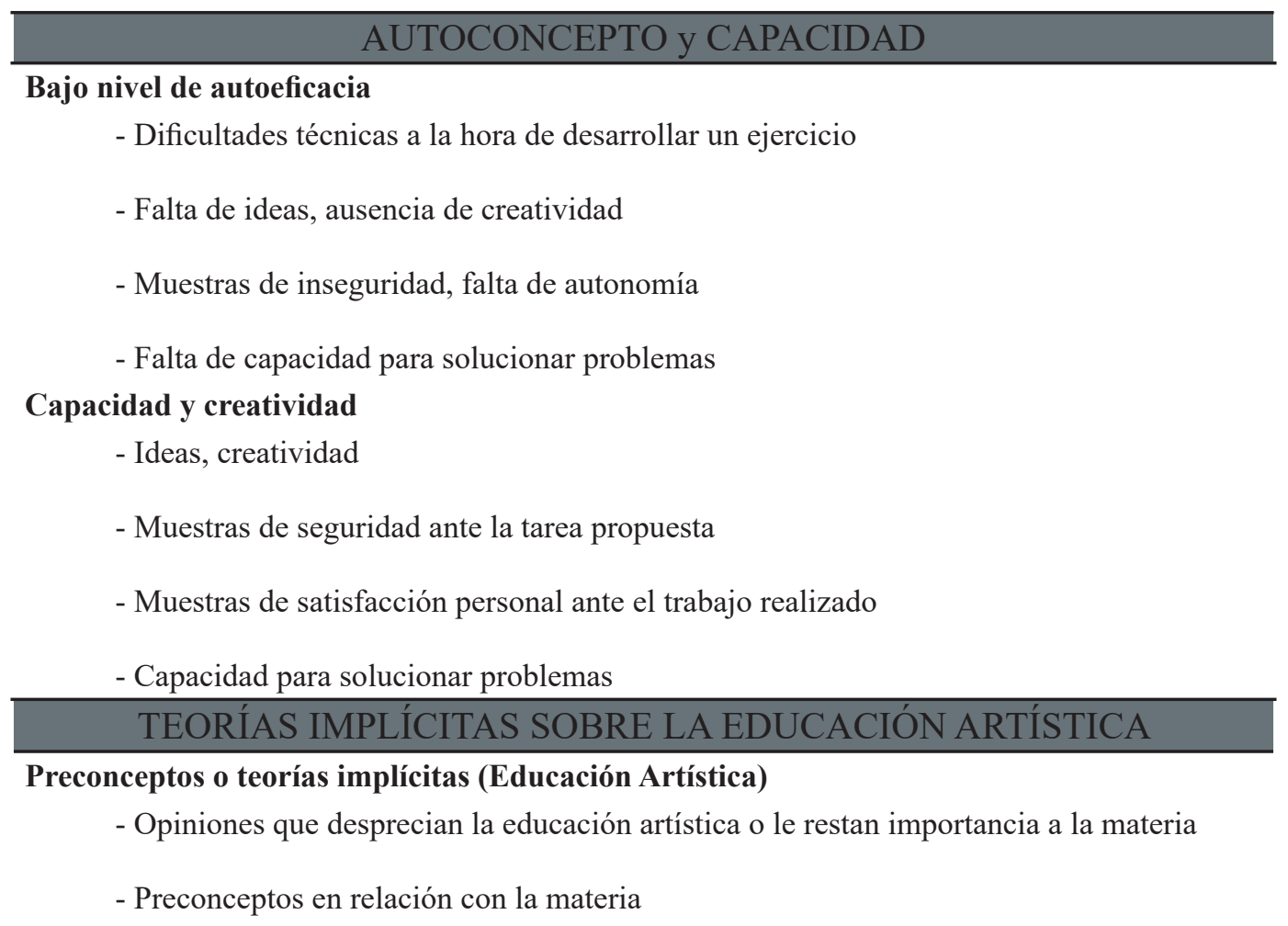

\section{Resultados}

Tomando como referencia el método usado como registro de la información y el periodo en el que se realiza, podemos distinguir dos apartados, un primer apartado que se corresponde con el diario de campo y a las observaciones realizadas en el primer trimestre de curso, y un segundo apartado correspondiente a las actividades realizadas con el alumnado a partir del cuarto mes de curso que nos ayudan a confirmar las observaciones previas.

\section{Primer trimestre: autoconcepto y creencias de autoeficacia}

Durante esta primera fase de la investigación la metodología didáctica utilizada es la usada tradicionalmente en EPVA, que consiste en una explicación o propuesta de ejercicio y la realización de dicha actividad por parte del alumnado. Desde que se plantea el primer ejercicio, que pretende escapar de los retratos perfectos y parecidos a la realidad a los que los estudiantes están acostumbrados, la baja autoeficacia 
aparece asociada a la incomprensión: No sé cómo hacer una nariz decente, es muy complicado (Mei), Profe, no sé lo que estoy haciendo (Nelson).

Durante todo el proceso de la investigación, se manifiestan, en numerosas ocasiones, las inseguridades del alumnado ante los ejercicios requeridos, siendo habitual encontrarnos a varios estudiantes que ante la tarea propuesta 'están pensando', con el folio en blanco, porque, según afirman, 'no se me ocurre nada'. Esto ocurre especialmente en los ejercicios que requieren la generación de ideas nuevas, siendo mucho menos habituales cuando trabajamos con dibujo técnico, que supone un trabajo más pautado y menos creativo. También es habitual que los estudiantes se quejen cuando les pedimos que se pongan a trabajar: Es que esto es muy difícil o es que yo no sé.

Llaman la atención sus bajas creencias de autoeficacia, que se repiten durante todo el periodo observado en todos los grupos, y que provocan, como efecto indeseado, una gran falta de autonomía. Así, es habitual que expresen sus dificultades como una petición de ayuda hacia la profesora: ¿Es así? ¿Esto vale? No sé si lo estoy haciendo bien (Leticia); Es que no estoy segura, ¿Podría valer algo asi? (Emma). Dulce y Jeny hacen una valoración negativa cada una de su respectivo ejercicio: Está quedando un poco mal pero bueno..., ;Vaya churro! Germán solicita ayuda directa a la profesora: Profe, no sé cómo hacer una estrella. ¿Me dibujas tú una? Si bien, también debemos indicar que ciertos alumnos/as, según avanzamos las clases, van ganando confianza.

Además, existen estudiantes que expresan sus bajas creencias de autoeficacia manifestando falta de evolución en los últimos años, como si se hubieran quedado en la etapa infantil. Elisa: Profe, necesito ayuda, no he evolucionado nada desde los 3 años. Deja de torturarnos, esto es un horror. ¿Esto vale? Parece dibujado por un niño de 4 años, pero bueno... (Begoña).

En algunas ocasiones, los estudiantes afirman que sí tienen ideas, pero que no saben cómo desarrollarlas, indicando que les faltan habilidades técnicas: Tengo una idea, pero no sé cómo dibujarla (Marcos); ¿Cómo se dibuja un perro? (Leticia), la misma alumna expresa su dificultad frente a otras tareas: No sé colorear, si lo coloreo lo estropeo. Profe, no sé dibujar. Sofía avanza lentamente: ¿Esto vale así? ¿Cómo puedo sombrearlo?; David se queja: Es que a mí no me sale, profe. En esta misma línea, un número elevado de alumnos/as manifiestan la ausencia de ideas, especialmente en las primeras semanas de clase: Yo voy a copiar eso, no tengo imaginación (Nuhacet), No sé si está bien, pero no se me ocurre nada más (Pamela).

También debemos indicar que a esta ausencia generalizada de ideas durante el primer mes le sigue un periodo en el que algunos estudiantes ganan en seguridad y comienzan a dar muestras de ello a la profesora. No obstante, nuevamente se observa que son capaces de expresan sus ideas, pero sus folios siguen en blanco, las ideas están solo en sus cabezas, las saben verbalizar, pero no representar, no 
NAVARRETE, RODRÍGUEZ \& BELVER / Educación artística y teorías implícitas del alumnado de educación secundaria

parecen acostumbrados a expresarse a través del dibujo: Profe, ya sé lo que voy a hacer (Jenny), Tengo una idea profe, ya verás, va a quedar muy bien (Bea). Ambas alumnas expresan sus ideas, sin embargo, como les sucede también a muchos compañeros/as, todo el desarrollo creativo es mental y no muestran más que la idea final que, muchas veces, no se acerca a lo que ellos tenían en mente.

Asimismo, son pocos los casos de alumnos/as que durante este primer cuatrimestre expresan su satisfacción ante el trabajo bien hecho, aunque existen algunos casos puntuales. Son alumnos que, pasadas unas semanas del curso, comienzan a ganar autonomía y comprensión del método de trabajo. Esto es arte, esto es pasión! (Blas); ;Soy un hacha! (Jenny); Profe, soy un genio (Andrés).

Los estudiantes van ganando autonomía, tras insistirles en repetidas ocasiones en que no deben preocuparse tanto por los resultados y que lo que se valora es la mejora y el esfuerzo. Aun así, les cuesta entenderlo, en general no se ven capaces de mejorar: 'Yo no soy Picasso' o 'yo no he nacido para esto' comentan a menudo. Todo esto afecta a la calidad de los ejercicios que presenta el alumnado, existiendo un número elevado de estudiantes que no entrega a tiempo o que lo hace de forma poco satisfactoria: ejercicios incompletos o que no se ajustan a lo esperado.

\section{Segundo trimestre: aplicación de ABP}

Una vez finalizado el primer trimestre, y antes de llevar a cabo un cambio de metodología didáctica, se pide al alumnado participante una reflexión sobre la materia: ¿Qué es la Plástica? y ¿Qué no es la Plástica? Para conocer sus opiniones se les pide su intervención en un corcho virtual o "linoit' que se publica en el blog de la profesora usando un post-it azul para expresar qué es la Plástica, y un post-it amarillo para expresar lo que no es. Se pide al alumnado que se identifique únicamente con sus iniciales. (Fig. 1)

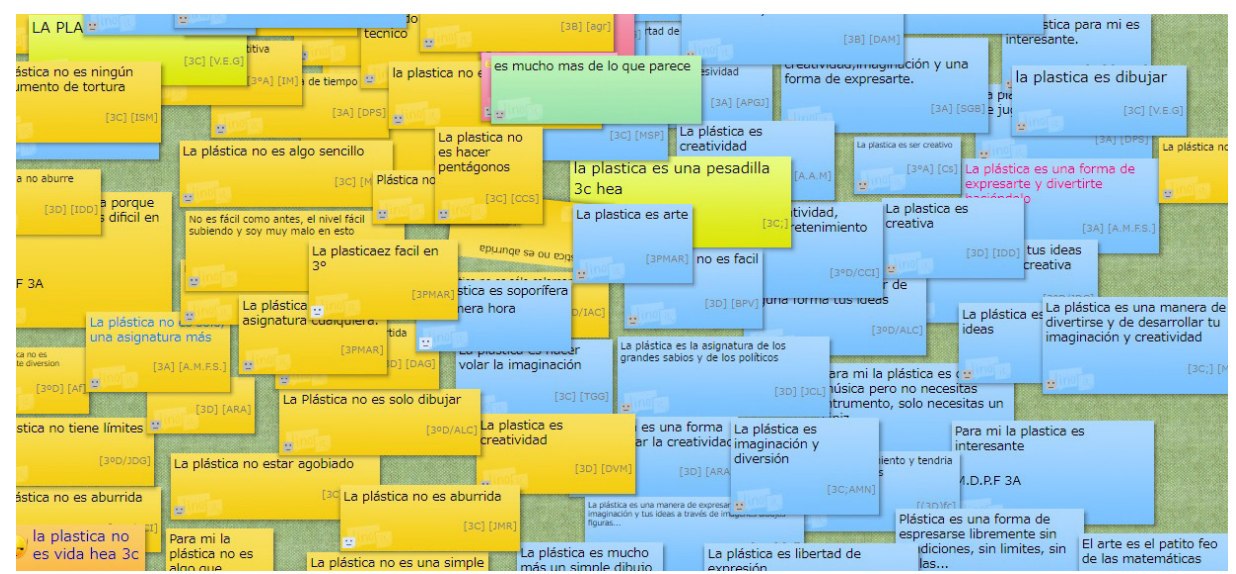

Figura 1. Imagen del Linoit. Fotografía de los autores/as.

1. Un 'Linoit', según se explica en el blog Educacontic, 'es un servicio de la web 2.0 que permite crear tableros o corchos virtuales para compartir recursos, ideas, materiales, etc. 
A partir de la actividad de reflexión realizada por el alumnado se comienza a aplicar un primer proyecto colaborativo en el aula que busca romper con las metodologías tradicionales y ayudar al alumnado a plasmar, de forma visual, su opinión sobre la Educación Artística. Para ello se comienza creando una obra colaborativa entre toda la clase: cada estudiante tiene un máximo de 3 minutos antes de pasarle la lámina al compañero/a. Se anima al alumnado a crear sin miedo y a dibujar de forma automática, utilizando diferentes técnicas gráfico-plásticas.

\section{Reflexiones en el corcho virtual}

Entre las intervenciones del alumnado acerca de lo que no es la Plástica la respuesta más repetida hace referencia a que la Plástica no es aburrida, repetitiva o monótona $(n=23)$. La segunda idea que encontramos con más frecuencia es la referida a la dificultad que entraña la materia, existiendo 12 alumnos que afirman que la Plástica no es algo fácil o sencillo. Además, un alumno lo enlaza con sus bajas creencias de autoeficacia: 'No es fácil como antes, el nivel está subiendo y soy muy malo en esto'. En contra de estas opiniones hayamos cuatro alumnos que opinan que 'la plástica es fácil' o que 'no es un instrumento de tortura'.

Existen varias intervenciones $(\mathrm{n}=10)$ que amplían y enriquecen la definición de la asignatura, entre ellas la más repetida: 'La Plástica no es solo dibujar o dibujar bien'. Otras consideraciones de interés son: 'La plástica no es solo una asignatura más', 'la plástica no es una simple manera de matar el tiempo', 'La plástica no tiene límites', 'La plástica no es una asignatura cualquiera', 'La plástica no es solamente diversión'.

Encontramos 6 opiniones en contra de la materia y sobre las emociones que ésta provoca: "La plástica no es divertida o entretenida, aburre' y varias referencias al dibujo técnico que parece rechazado por un número reducido de alumnos $(\mathrm{n}=5)$ : ' $\mathrm{La}$ plástica no es hacer pentágonos ' La plástica no es matemáticas'.

Existen 2 referencias a la falta de necesidad de estudiar la materia: 'Para mí la plástica no es algo que estudiar' 'La plástica no se suspende', teorías implícitas probablemente desarrolladas la Educación Primaria. Finalmente, dentro del apartado de lo que no es Plástica, encontramos cinco opiniones que no aportan gran cosa: 'Esto no es una pipa"'

En cuanto a 'qué es la Plástica' para nuestro alumnado comprobamos que aparece, en la mayoría de los casos, asociada a la creatividad, imaginación y expresividad: 'La plástica es creatividad, imaginación y una forma de expresarte' ( $\mathrm{n}=38)$, de los cuales además 3 de ellos hacen referencia a la diversión asociada a este hecho: ' $L a$ plástica es una forma de expresarte y divertirte haciéndolo'. Otros 6 alumnos/as hacen referencia a la diversión, el entretenimiento y lo interesante de la materia. 
Por otro lado, los estudiantes valoran la materia $(\mathrm{n}=14)$ : 'Es bonita', 'es mucho más de lo que parece', 'no es una tontería', 'es fascinante', 'es un arte', 'es una asignatura donde puedes aprender mucho'. Por último, encontramos 6 opiniones negativas de diverso tipo que reducen la materia a dibujar y pintar y otras 6 opiniones que no aportan nada.

\section{Proyecto colaborativo}

La actividad colaborativa, en el momento de su planteamiento, provoca sorpresa en el alumnado. Inicialmente, cuando cada uno de los grupos accede al aula se encuentra con un cambio en la disposición de los pupitres, que están en forma de U y no mirando al frente como es habitual. Ante la explicación del ejercicio los estudiantes se encuentran un poco perdidos, se les pide que se expresen sobre el papel de forma automática, pensando en lo que para ellos es la materia de EPVA. El grupo de alumnos/as de $3^{\circ}$ PMAR son los que se encuentran con más dificultades, se quedan parados, alegan que están pensado y preguntan continuamente a la profesora: Pero ¿cómo hago el dibujo? ¿Grande o pequeño?, pregunta Pedro; No tiene que tener sentido ¿no?, (Bea). Al finalizar la sesión con el grupo, los estudiantes en prácticas y yo misma concluimos que les ha costado mucho resolver el ejercicio.

Con los siguientes grupos los resultados son algo mejores, aunque siempre partiendo de un bloqueo inicial del alumnado que no se atreve a intervenir ante el papel en blanco: ¿Lo hacemos grande o pequeño?, pregunta Lucas a la profesora; ¿Lo que nosotros queramos?, pregunta Iker que parece no tener clara la propuesta del ejercicio. Algunos alumnos/as manifiestan las mismas inseguridades que al principio de curso: Es que no sé qué hacer, no sé qué dibujar (Aitana); Yo esto no lo entiendo (Amalia); No se me ocurre nada (Mei) o Yo esto no sé (Nuhacet).

Según avanzan la sesión algunos alumnos/as empiezan a disfrutar del ejercicio y de la posibilidad de crear libremente, incluso estudiantes que eran apáticos al inicio de curso. Sin embargo, aproximadamente un 10\% de ellos no aportan nada nuevo a los ejercicios que llegan a sus manos y se limitan a completar lo que otros han iniciado, eso sí, respetando siempre lo dibujado previamente por los compañeros/ as. Gloria, que en clases previas estaba insegura, parece entusiasmada: ¿Puedo usar témperas? ¡Cómo estoy usando mi imaginación!; Aurora se muestra satisfecha con la tarea: ¡Qué rápido se me ha pasado hoy la clase!

Al finalizar las dos sesiones que nos ocupa la actividad los estudiantes parecen satisfechos con los trabajos realizados. Son ejercicios en los que, aunque encontramos algún cliché, como la paleta de colores o el pincel (que aparecen representados en 10 ejercicios), en general consiguen composiciones surrealistas y atrevidas en cuanto a forma y color que reflejan el que los estudiantes pongan en duda todas las normas establecidas respecto al arte y la Educación Artística. La mayoría de las composiciones están realizadas mezclando diversas técnicas: recortes de revistas, 
ceras, témperas, papeles de colores, carboncillo, etc. De esta forma, encontramos trazos abstractos mezclados con recortes de revistas con imágenes de personas o textos y algunos dibujos reconocibles de instrumentos de dibujo.

Además, en los ejercicios podemos encontrar varios textos, ya sean escritos por los estudiantes o seleccionados y recortados de revistas: 'Lluvia de ideas', 'El móvil te mira a los ojos', 'cambia el mundo y no pierdas un segundo', 'no temas a tus miedos, tienes que enfrentarte.', 'no es arte si te parte', 'el arte es bonito, son ideas, es pasión', 'no sé qué hacer ya', 'sólo necesitas un lápiz para empezar a crear', 'sé atrevida' o 'levanta la mano en plástica. Se repiten palabras sueltas como: 'imaginación', 'creatividad', 'dibujo', 'manualidad', 'sentimientos', 'abstracto', 'fusión', 'diversión', 'talentos' e 'ideas'. También podemos encontrar otras palabras sueltas sin sentido que acompañan imágenes y acentúan su carácter surrealista: 'Chanel n5', 'What?', 'percebe', '\#modelo', así como nombres propios de los alumnos y alumnas.

En esta actividad (Fig. 2), tanto las imágenes como los textos confirman que el alumnado asocia la materia con creatividad y la imaginación, pero también la persistencia de ideas preconcebidas como la asociación de esta con el entretenimiento, la idea clásica del pintor con la paleta y las manualidades.

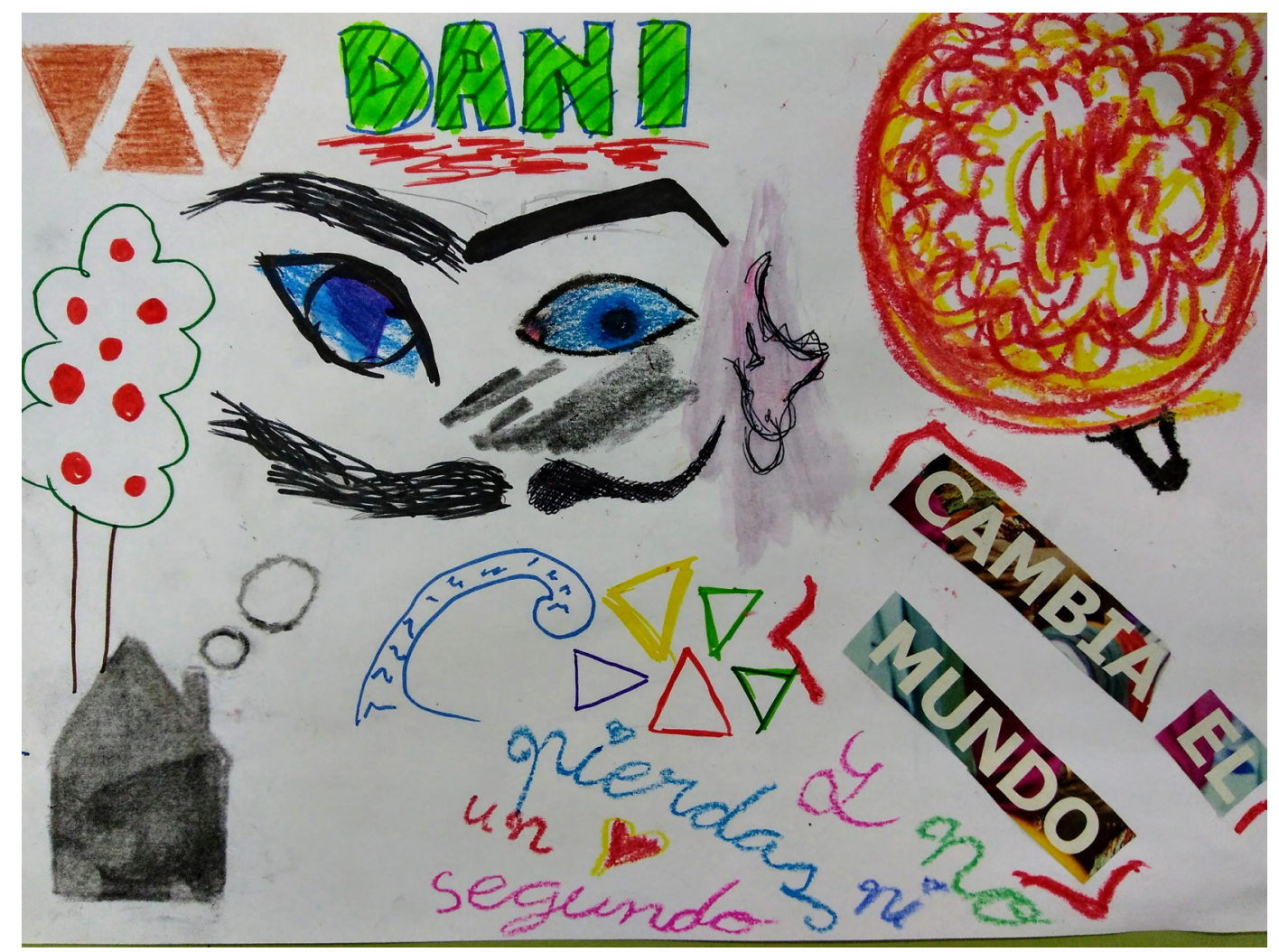

Figura 2. Ejercicio realizado por el alumnado. Fotografía de los autores. 
NAVARRETE, RODRÍGUEZ \& BELVER / Educación artística y teorías implícitas del alumnado de educación secundaria

\section{Conclusiones y discusión}

En la investigación descrita hemos analizado las opiniones y actitudes frente a nuestra materia (EPVA) expresadas tanto oralmente como por escrito o a través de representaciones gráfico-plásticas. En general comprobamos que existe un gran número de estudiantes que valora la EPVA, que se asocia con la expresividad y creatividad, incluso varios que expresan oralmente y a través del Linoit, la dificultad que supone para ellos y ellas la materia, en contra de la idea extendida de que es una asignatura fácil.

Nuestro estudio confirma que la mayoría de los mitos que enunciaba Giráldez en 2007 se mantienen, si bien es cierto que esto ocurre en un reducido porcentaje de estudiantes. Tal y como afirmaba la autora (Véase también Acaso, 2009), encontramos entre nuestro alumnado la idea que asocia la materia de EPVA con las manualidades y la diversión. Existen, por tanto, como sostienen Vaquero y Gómez del Águila (2018) alumnado que relega la materia a un segundo plano y que no relaciona el intelecto con la misma. El hecho de que muestren interés especialmente por las materias que consideran 'más importantes' connota que sigue latente la idea de que la EPVA es una materia sin importancia. Cabe señalar, como ya lo hace Ascaso-Til (2016) la influencia del entorno en la permanencia de estas ideas. Sin embargo, la mayoría de los estudiantes aprecian la materia y son conscientes de que pueden aprender tras varias clases prácticas, es decir, que no es un "don innato" al igual que lo hacían los estudiantes participantes en la investigación realzada por Morales-Caruncho y Chacón Gordillo (2018).

Por otro lado, constatamos cómo el alumnado en general asocia un dibujo bien hecho con una representación fiel de la realidad y es precisamente el hecho de sentirse incapaces de representarla lo que produce 'bloqueos' entre los estudiantes (Barbosa, 2004). Sorprende especialmente que pasado el tercer mes de clase, cuando se propone el ejercicio surrealista, los estudiantes vuelven a sentirse inseguros y no saben por dónde empezar. Llama la atención también que varios estudiantes opinen que no es necesario estudiar la materia o que no está ligada al dibujo técnico, expresando incluso que el dibujo debe ser totalmente libre y no condicionado por ninguna regla, esto se observa especialmente en las actividades prácticas realizadas a lo largo del cuarto mes.

En cuanto al autoconcepto y las creencias de autoeficacia, en línea con los estudios que asocian la percepción de las capacidades con la apatía (Paulov y Kambori, 2007) constatamos que existen varios estudiantes que no se sienten preparados y que, por tanto, no se atreven a realizar las tareas. De acuerdo con las teorías enunciadas por Lowenfeld y Brittain (1980), los estudiantes realizan una autocrítica a sus propios dibujos, incluso reconocen la falta de evolución. La existencia de varios estudiantes que dejan sus folios en blanco en las primeras semanas de clase constata el bajo grado de autoeficacia de estos, entroncando con la idea del 'artista genial' que sólo 
trabaja si se siente inspirado (Acaso, 2009, Araluce 2017; Eisner 2002, Reina, 2017; Romo, 1998).

Dados los resultados obtenidos consideramos necesario seguir indagando acerca de cómo las teorías implícitas y los preconceptos sobre la materia de EPVA en Secundaria o la llamada 'Plástica' en Educación Primaria influyen sobre la percepción que los estudiantes tienen sobre ella, y, por tanto, en su grado de autoeficacia, en su motivación y en sus resultados académicos. La constatación de la existencia de teorías implícitas también nos lleva a pensar cómo modificar las actitudes y preconceptos que son la causa de la falta de interés ante la materia de EPVA. En este sentido planteamos, en una segunda fase de la investigación, la aplicación de metodologías didácticas activas, como el aprendizaje basado en proyectos (ABP), para modificar preconceptos y servir de fuente de evidencias para la mejora del proceso educativo.

\section{Referencias}

Acaso, M. (2009). La educación artística no son manualidades. Nuevas prácticas en la enseñanza de las artes y la cultura visual. Madrid, España: Catarata.

Araluce, J.(2017). Behartokia: ikusi-ikasi-sortu. Propuesta sobre cómo la Educación Plástica se puede articular para despertar la motivación del alumnado de ESO, y así explorar, sentir, transformar, crear y compartir. (Tesis doctoral.) Universidad del País Vasco, España. Recuperado de: https://core.ac.uk/download/pdf/132351154.pdf

Ascaso-Til, I. (2016). Relación entre la percepción y la motivación que presentan, ante la Educación Plástica y Visual, los alumnos y profesores de Secundaria de un centro de Huesca. (Trabajo Fin de Máster). UNIR, España. Recuperado de: https:// reunir.unir.net/handle/123456789/3950

Barbosa, B. (2004). La estampa en la Enseñanza Primaria. Metodología para la Plástica. Málaga, España: Aljibe.

Belinche, D., y Ciafardo, M. (2006). Los estereotipos en el arte: un problema de la educación artística. II Jornadas de Investigación en Disciplinas Artísticas y Proyectuales (La Plata). Recuperado de: http://sedici.unlp.edu.ar/ handle/10915/39164

Cisterna Cabrera, F. (2005). Categorización y triangulación como procesos de validación del conocimiento en investigación cualitativa. Theoria, 14(1), 61-71.

Díaz de Rada, A. (2011). El taller del etnógrafo. Materiales y herramientas de investigación en Etnografía. Madrid, España: UNED. 
NAVARRETE, RODRÍGUEZ \& BELVER / Educación artística y teorías implícitas del alumnado de educación secundaria

Eisner, E. W. (2002). Ocho importantes condiciones para la enseñanza y aprendizaje en las artes visuales. Arte, Individuo y Sociedad, anejo 1, 47-55.

Giráldez, A. (2007). Competencia cultural y artística. Madrid, España: Alianza Editorial.

Hernández, F. (1995). El diseño curricular de educación visual y plástica un análisis crítico. Revista interuniversitaria de formación del profesorado, 24, 21-37.

Lowenfeld, V., y Brittain, W. L. (1980). Desarrollo de la capacidad creadora. Buenos Aires, Argentina: Kapelusz.

Morales-Caruncho, X., y Chacón Gordillo, P. (2018). Los futuros docentes y la enseñanza de las artes visuales. Un estudio basado en la creación artística como forma de interrogar la realidad. Infancia y Aprendizaje, 41(2), 287-324. doi: $\underline{10.1080 / 02103702.2018 .1434036}$

Paulov, V. y Kambouri, M. (2007). Pupils' attitudes towards art teaching in primary school: an evaluation tool. Studies in Educational Evaluation, 33, 282-301. doi: 10.1016/j.stueduc.2007.07.005

Reina, F. M. (2017). El profesor de Educación Plástica y Visual y los imaginarios. (Tesis doctoral). Universidad de Sevilla, España. Recuperado de: https://dialnet. unirioja.es/servlet/tesis? codigo $=108414$

Romo, M. (1998). Teorías implícitas y creatividad artística. Arte, Individuo y Sociedad, 10, 12-28.

Vaquero, C., y Gómez del Águila, M. L. (2018). Educación artística, desconsideración social y falta de expectativas. Consecuencias de la reproducción como paradigma no-educativo. EARI. Educación Artística Revista de Investigación, 9, 220-236. doi: 10.7203/eari.9.12051 